\title{
Design and construction of test facility for evaluation of swell packers in cased and open holes
}

\author{
Tasneem Pervez $^{1} \cdot$ Sayyad Zahid Qamar ${ }^{1} \cdot$ Maaz Akhtar $^{2} \cdot$ Moosa Al Kharusi ${ }^{1}$
}

Received: 2 April 2021 / Accepted: 24 August 2021 / Published online: 7 September 2021

(c) The Author(s) 2021

\begin{abstract}
In the petroleum industry, packers refer to the components/products which are used to isolate one section in a formation from others, or to isolate the outer section of a production tubing from the inner section, which may be a casing or a liner or the wellbore itself. Mechanical packers are installed through some form of tubing movement. Permanent packers are low in cost and provide better seal. Retrievable packers have lower sealing capability but are re-usable after repair, and therefore expensive. More innovative packers made of swellable elastomers are rather new. These elastomers swell when they come in contact with different types of fluids (mostly water and oil). Like a casing, these new packers are lowered to the desired depth and allowed to swell before production or injection operations begin. Various studies have been published about the swelling and mechanical response of these elastomers. However, many questions remain about the sealing performance of swell packers, and their effectiveness in actual wellbores of rough and random profiles. This paper describes the design and development of an experimental unit for performance testing of a mix of inert and swelling elastomer seals under realistic well conditions. Actual swell packers and petroleum tubulars are housed in a concrete block that replicates open-hole and cased-hole wells through layers of varying roughness. This is a one-of-its-kind unit providing full-scale demonstration about the working of swell packers against outer casing or rock formation in a wellbore. It is also a complete testing apparatus to investigate the behavior of swell packers made of fast-swell and medium-swell elastomers, and how they seal off irregular boreholes. This work can provide basic understanding and visual corroboration to petroleum engineers and students, swelling elastomer application developers, and academic and research personnel.
\end{abstract}

Keywords Testing-demonstration unit · Design and construction $\cdot$ Swell packer $\cdot$ Swelling elastomer $\cdot$ Water-swell $\cdot$ Oilswell $\cdot$ Open-hole $\cdot$ Cased-hole $\cdot$ Formation roughness

\section{Introduction}

Packers are used in petroleum drilling and development to isolate one section in a formation from others, or to isolate the outer section of a production tubing from the inner section, which may be a casing or a liner or the wellbore itself (Glossary 2019). Sometimes, referred to as mechanical packers, they remain in an oil well during its production life and are set in position by various types of tubular movement. In a typical well, a packer is installed close to the bottom

Sayyad Zahid Qamar

sayyad@squ.edu.om

1 Mechanical and Industrial Engineering Department, Sultan Qaboos University, Muscat, Oman

2 Mechanical Engineering Department, N.E.D, University of Engineering \& Technology, Karachi, Pakistan end of the production line, just above the top perforations (PetroWiki 2019). If a well is connected to multiple reservoir zones, the packer is also used to isolate the perforations for each zone. It may also be used to isolate sections of corroded casing and casing perforations, to protect the casing from undesirable fluids, and to completely shut-off high water-cut zones. They are further classified into two types. Permanent packers have the twin advantages of lower cost and more effective sealing (Triolo et al. 2002). Retrievable packers, on the other hand, are somewhat low on sealing performance, but are more expensive as they can be repaired and re-used (Bell et al. 1972; Wikipedia 2019). Temperature and pressure can cause changes in the expansion rate of production tubing and packer leading to the development of tensile or compressive force conditions.

Until the advent of novel swellable elastomers, the most commonly used packers were the ones mentioned above.

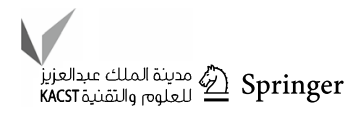


A swell packer is much simpler than a mechanical packer because there are no moving parts and it requires no special services. Typically, the elastomers are vulcanized on a steel pipe to make a swellable packer. Similar to a casing, the packer is taken down the well to the target location. These rubbers swell when they come in contact with different types of fluids and are categorized accordingly as oil-based or water-based swelling elastomers (Dorohov et al. 2016; Akhtar et al. 2018a). When exposed to water or crude oil, the elastomer segment swells and completes the seal, before the commencement of production (Akhtar et al. 2018b). The swelling continues until the internal stresses inside the elastomer reach equilibrium and creates a differentially sealing annular barrier, hence completing the sealing (Rigzone 2019). The swelling amount of these elastomers depends on the fluid chemistry and the operating temperature. Swell packers are often used in conjunction with solid expandable tubular (SET) technology (Qamar et al. 2012a).

Swell packers have made it possible to restart production from discarded or diminishing wells in a profitable manner. By successfully shutting off water or gas, use of these packers has resulted in higher recovery from aging wells. Swell packers have also brought down drilling costs and achieved reduction in the size of oil rigs through completions without cement, or with reduction in the amount of cementing. Many of these new techniques are together referred to as enhanced oil recovery EOR (Pervez et al. 2007; Kamal and Sultan 2019).

In field applications, different types of swellable elastomers are used at different depths of the same well, or in different wells. Extensive amount of research has been carried out for material and mechanical characterization of swellable elastomers in virgin or vulcanized form, as well as in borehole conditions (Zeidan et al. 2018; Al-Yami et al. 2008). Some researchers have tested laboratory-size elastomer samples under different temperatures and saltwater concentrations (Patel et al. 2019; Qamar et al. 2009, 2016; Pervez et al. 2012). However, uncertainty remains about the effectiveness of actual sealing achieved by a swellable packers. Is the packer really effective in terms of providing the needed pressure to keep the unwanted fluid away from seeping into the production tubing? Does the swelling elastomer segment completely cover the random profile of the formation in open boreholes or the roughness of a casing in cased holes? No tests have been carried out in the real oilfield scenario: elastomer seals mounted on tubulars in cased or open holes, with or without cementing.

\section{Current work}

Work presented in this paper covers the performance assessment of different elastomer materials and packer sizes through the development of an experimental-cum-demonstration unit. This test setup is designed and fabricated using actual packers: segments of inert and swelling elastomers vulcanized onto petroleum pipes/tubulars. All of these are placed inside a concrete block that emulates actual open-hole and cased-hole wellbores. The inner-most pipe is a swell packer comprising of inert and swelling elastomer segments sealing against a casing pipe. Another set of swelling elastomers is mounted on the outside of this tubular, and swells to seal against the formation, in the form of a concrete block with layers of varying roughness as would be the case in a real formation (Qamar et al. 2012b; Pervez and Qamar 2011).

This is the only setup of its kind, with several key objectives: Life-size demonstration of how a swell packer seals against an outer steel casing or against the rock formation in a wellbore; investigation of the swelling response of a rapidswell (E1) and a medium-swell elastomer (E2) in shallow aquifer type wells (almost ambient conditions); and experimentation and visual display of how the swelling elastomer segments provide sealing against uneven formations and irregular surfaces. Commercial names (or numbers) of the elastomers and packers are not mentioned due to confidentiality requirements.

\section{Conceptual and detail design}

Many feasible conceptual designs were developed for this experimental unit. The following set of criteria reduced the possible designs to only a few. The formation roughness of typical on-shore oil-field should be replicated as closely as possible. The casing, production tubing, and swell packers (along with the spacing between these) should be the same as used in an actual oil wells. The spacing between open-hole and packer, and cased-hole and packer must be filled with fluids having specifications very close to those of borehole liquids. Swelling behavior of the elastomer must be clearly visible and recordable during the swelling process (several months). It should be possible to de-swell the elastomers after complete sealing, and to re-swell again, to study the effect of the swell/de-swell/re-swell cycle. After several rounds of conceptual design and evaluation, detail design was developed for the selected best concept, satisfying all of the above criteria.

The final design consisted of a half concrete block replicating the formation. Two cutaway half sections of actual swell packers were fitted inside the concrete half-block. This way there were two concentric packers, the inner one sealing against the steel casing of a larger-diameter packer, and the outer one against the concrete block (borehole formation). There were sections of both inert and swelling elastomers. The inside (semicircular) surface of the concrete block was of varying diametral sizes and roughness to duplicate actual 
rock formation environment. This multi-packer unit had to be encased (leak-proof sealing to withstand high pressures) inside high-strength plexi-glass, so that the internal configuration and the progressive swelling could be clearly observed from the top and the front. Figure 1 shows the final arrangement, layout, and details of this experimentaldemonstration unit.

The finished design had the following key specifications and features: a concrete half-block with a height of $1280 \mathrm{~mm}$, width of $827 \mathrm{~mm}$, and thickness of $427 \mathrm{~mm}$; a semicircular cavity in this concrete block consisting of many sections of $80 \mathrm{~mm}$ height, each with a different surface roughness. This semicircular cavity was to have a diametral variation ( $311 \mathrm{~mm}$ to $320 \mathrm{~mm}$ ) to match the crock formation of an actual regional oil well. Inside packer consisted of two elastomer segments of inert and swellable type; elastomer on $177.8 \mathrm{~mm}$ tubular swells against $244.475 \mathrm{~mm}$ casing. Outside packer consisted of quick-swell elastomer mounted on $244.475 \mathrm{~mm}$ casing that swells against $311.5 \mathrm{~mm}$ formation (concrete block). Testing parameters, emulating shallow aquifers in actual oil wells, included normal water (near-zero salinity), and ambient conditions of about $20^{\circ} \mathrm{C}$ temperature and atmospheric pressure.

\section{Fabrication and assembly}

In consultation with oilfield engineers, and following the recommendations of concrete requirement for oil well cementing jobs, a specific concrete mix was made, targeting good strength, endurance, and short curing time. A cylindrical wood pattern of required height was prepared, and a polystyrene sheet of preset thickness was mounted on it. On an extended-length lathe machine, various sections of $80 \mathrm{~mm}$ height were engraved on the polystyrene with different diameters and different values of surface roughness. This polystyrene-covered wooden pattern was cut lengthwise into two semi-cylindrical halves. Inserting this piece as a core, the specially prepared concrete mix was poured into a prefabricated oversize wooden pattern. Once the concrete was sufficiently cured, the wooden pattern was taken apart, the polystyrene core was stripped off, and the concrete halfblock was thoroughly scrubbed. Figures 2 and 3 outline this process, also showing a blowup of the distinctly different sections with respect to diameters and surface roughness. The elastomer-mounted packers were precisely halved longitudinally, to be used as the inner and outer tubes in the test assembly; Figure 4. The cutaway steel tubulars and elastomer packers were cautiously placed and fitted inside the concrete semi-cylinder. To complete the assembly, plexiglass sheets were fitted to form the see-through walls at the top and front. A hook-type lifting mechanism was fixed at the top (Figs. 5 and 6) to move the full assembly as required, using overhead crane or other moving/lifting equipment.

The most challenging design task was to make the whole unit leak-proof. Many common techniques were not suitable, as it had to be guaranteed that the assembly will remain leakproof even after substantial swelling of elastomers, which can exert enormous pressures. A detailed comparative study was carried out for all available varieties of weather-shield paints, and their merits and demerits, but all had to be discarded due to pressure sustainability requirements. Finally, a
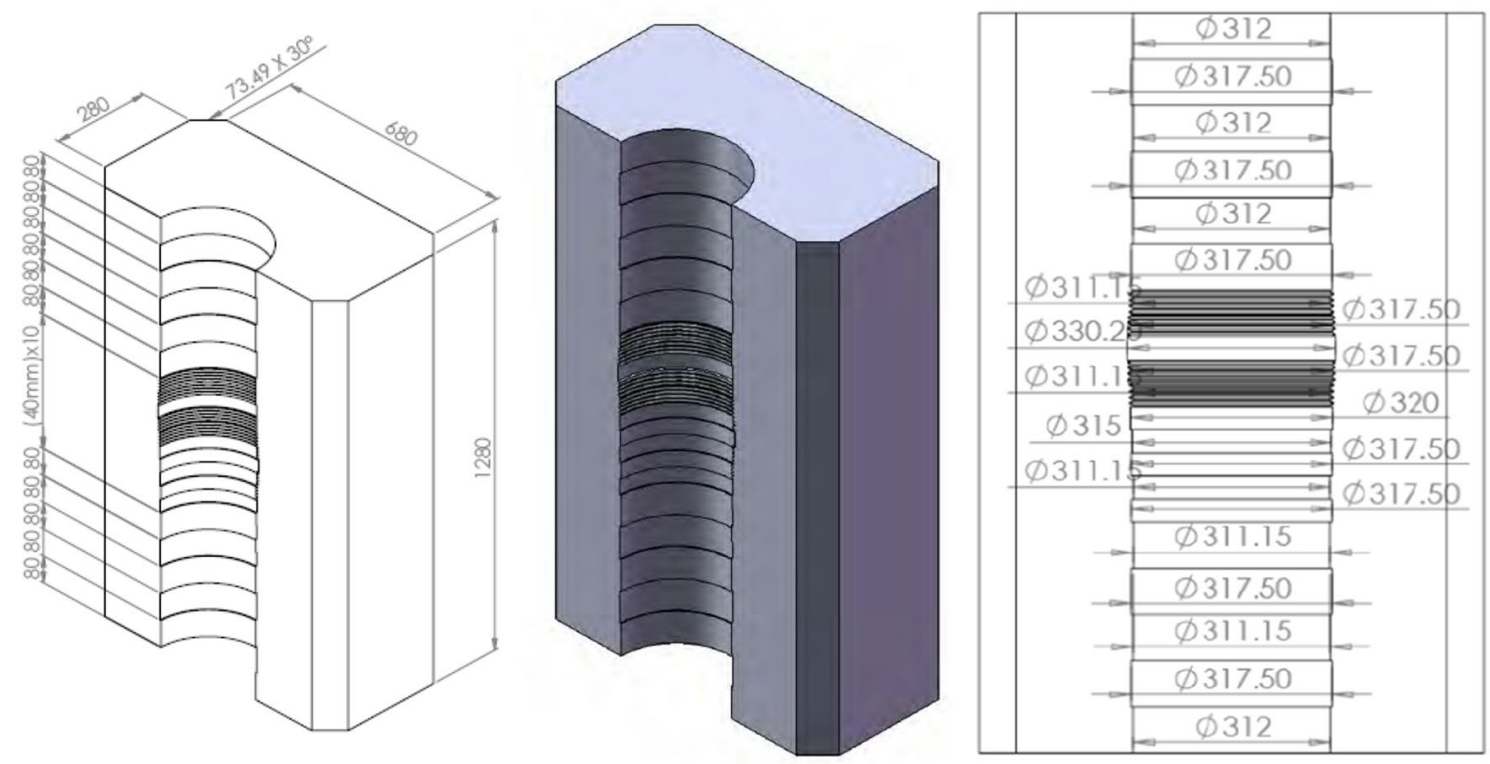

Fig. 1 Concrete half-block having 80-mm sections with varying diameters and surface roughness to replicate the drilled formation 
Fig. 2 Concrete filling into wooden pattern of half-block fitted with polystyrene core, and curing of the assembly
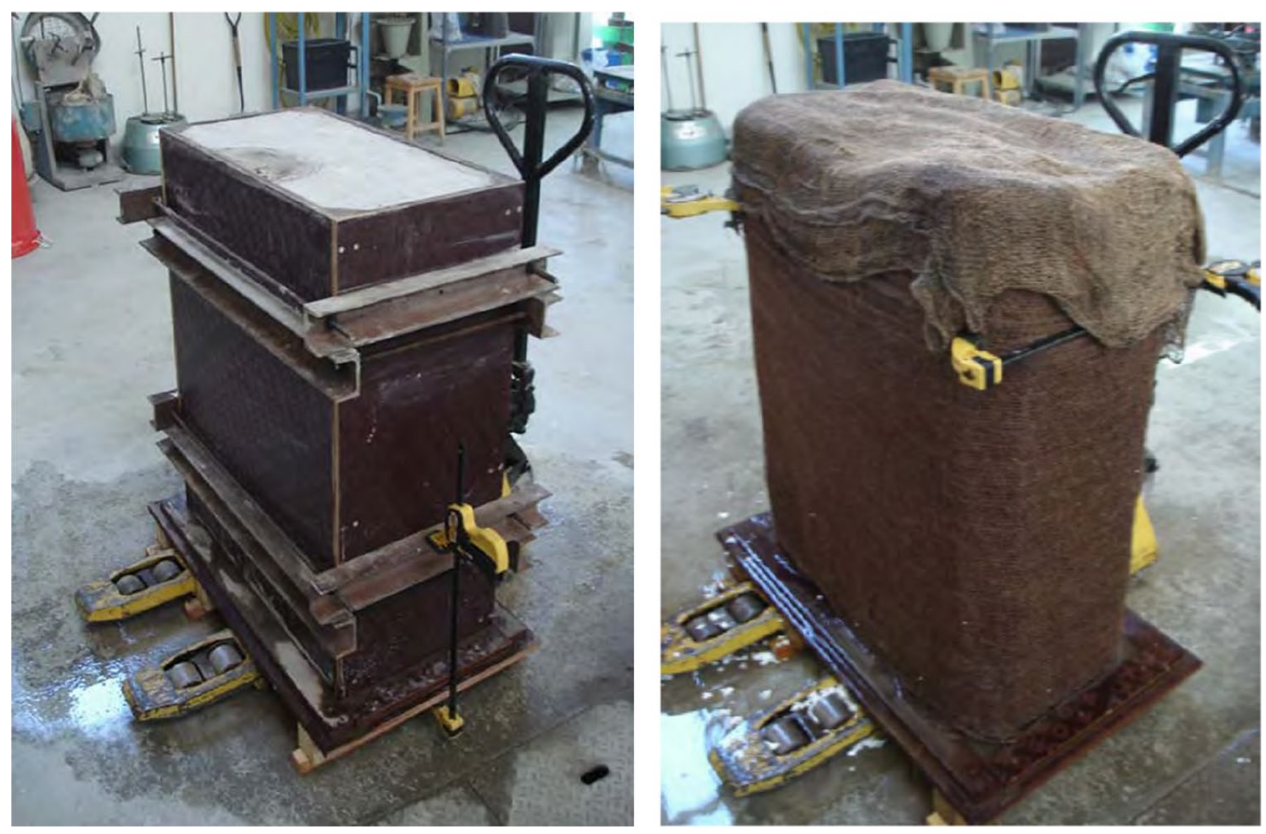
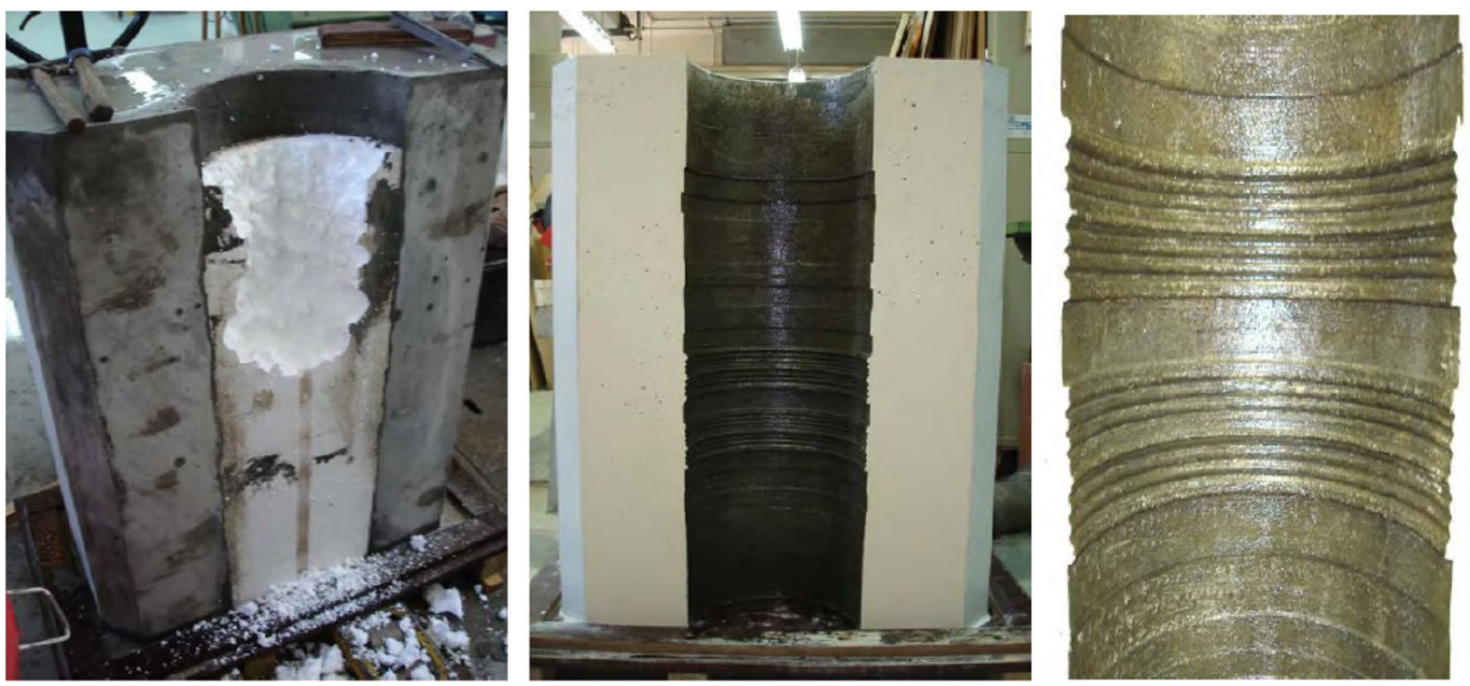

Fig. 3 Removing of polystyrene core (left); finished geometry (middle) and enlarged view (right) of concrete half-block having diameter and roughness variations

carefully selected epoxy coating was smeared onto the walls before the plexi-glass sheets were bolted into position. Similarly, a combination of Tank-Guard 1 and 2 paints from Jotun Marine Paints Division was applied on the inside surface of the concrete half-block so that it could remain water-proof even when filled with water for several years. The torque to be applied on the bolts for fastening of plexi-glass sheets to the concrete block was calculated using standard procedure outlined in design of fasteners (Norton 2013).

At the end, the purpose-built screw at the top was taken out, water was filled into the test setup using a proper-size funnel, and the screws were retightened. A photographic unit was set up, auto-programmed to take sharp-focus pictures of the swelling elastomer sections at fixed intervals of time. Photographs and videos were also recorded manually to observe the swelling process.

\section{Results and discussion}

After observing and monitoring the swelling behavior of the packers for a few days, it was found that the steel tubulars and screws/bolts exposed to water had started to corrode. This would have only a minor effect on swelling. However, 

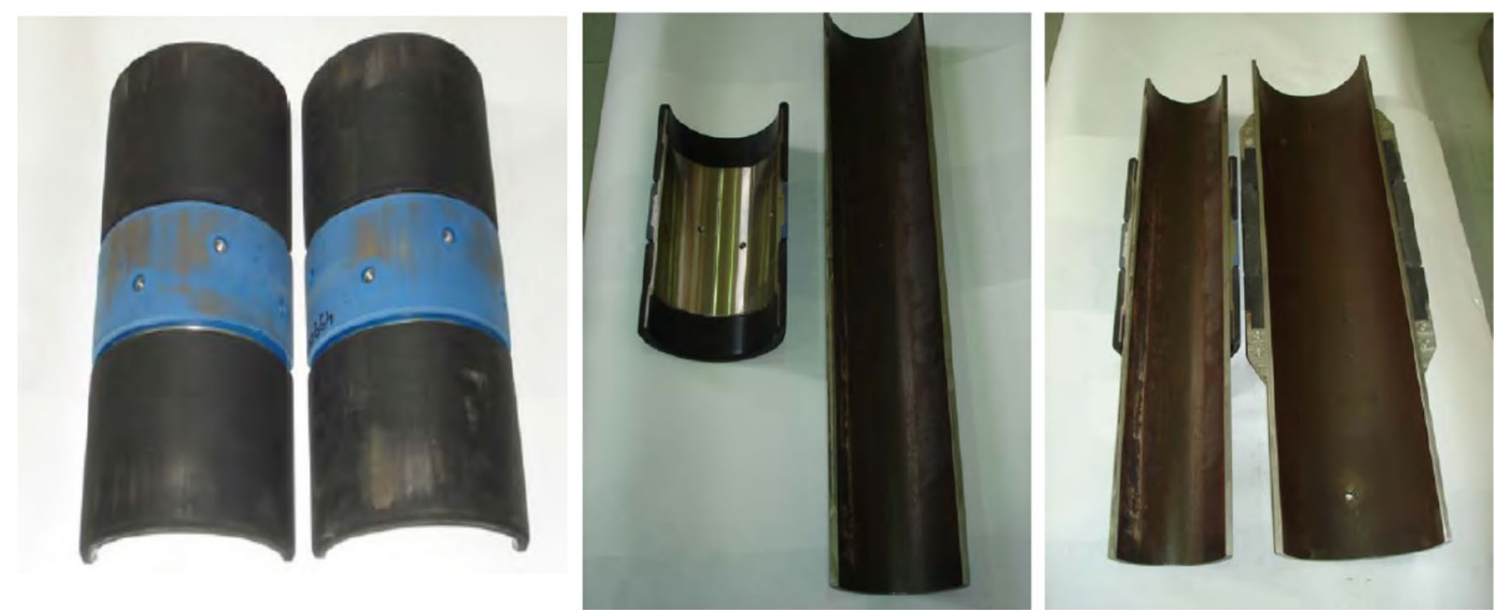

Fig. 4 Half sections of inner medium-swell packer (left) and outer fast-swell packer (middle), fitted on corresponding steel tubulars (right)

Fig. 5 Fitting of packer-tubular subassembly in the concrete block, and fixing of the lifting arrangement (left); attaching of the plexi-glass front wall (right)
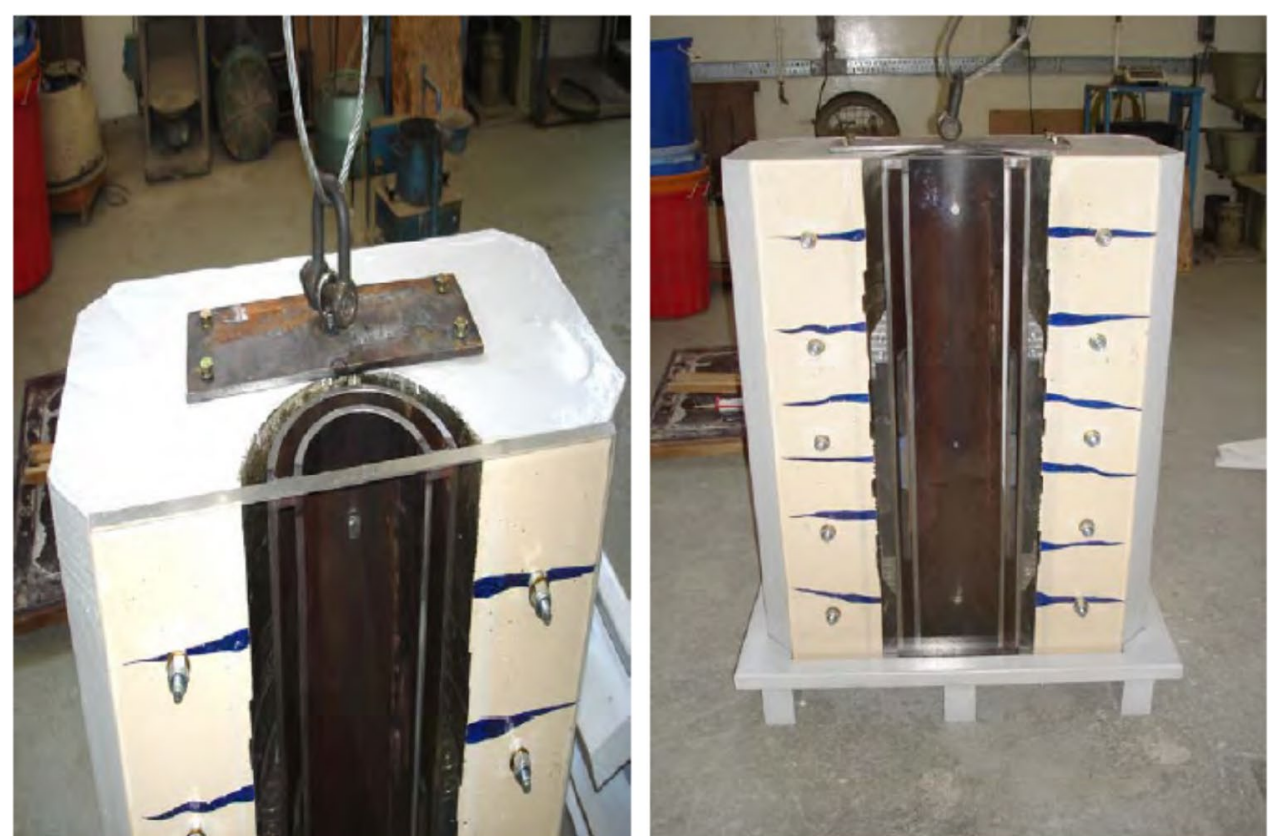

the rust particles diffused into the water and reduced visibility drastically as more corrosion took place; Figure 7. To remedy this problem, the water was siphoned off using a portable pump, and the rust stains and particles were vigorously cleaned. This flushing and cleaning of the unit improved the visibility significantly; Figure 8 .

The packer exhibited a far slower rate of swelling than expected. For operating conditions in shallow aquifer type wells $\left(50{ }^{\circ} \mathrm{C}\right.$ temperature and $1 / 2 \%$ salinity), it was expected that the elastomer would swell by about $70 \%$ in the outer packer (elastomer E1) in six hours, based on swelling tests conducted on laboratory-size samples (Patel et al. 2019; Qamar et al. 2009, 2016; Pervez et al. 2012), confirming its fast-swell character. Salinity of the normal water filled in the concrete block was almost the same. However, as the test assembly was housed in an air-conditioned laboratory, the operating temperature of around $20{ }^{\circ} \mathrm{C}$ was far lower than the well temperature. Earlier laboratory tests (Patel et al. 2019; Qamar et al. 2009, 2016; Pervez et al. 2012) reported a significant reduction in elastomer swelling for such a temperature difference. Also, the test packer was restricted to swell only radially outward and against a concrete wall of varying diameter and surface roughness. On the other hand, the laboratory-size elastomer samples were free to swell in all directions. Because of these situational differences, the packer elastomer fully swelled against the uneven concrete surface in just over 10 days. 
Fig. 6 Top and front views of the assembled setup showing inner and outer packers, plexiglass walls, and lifting hook
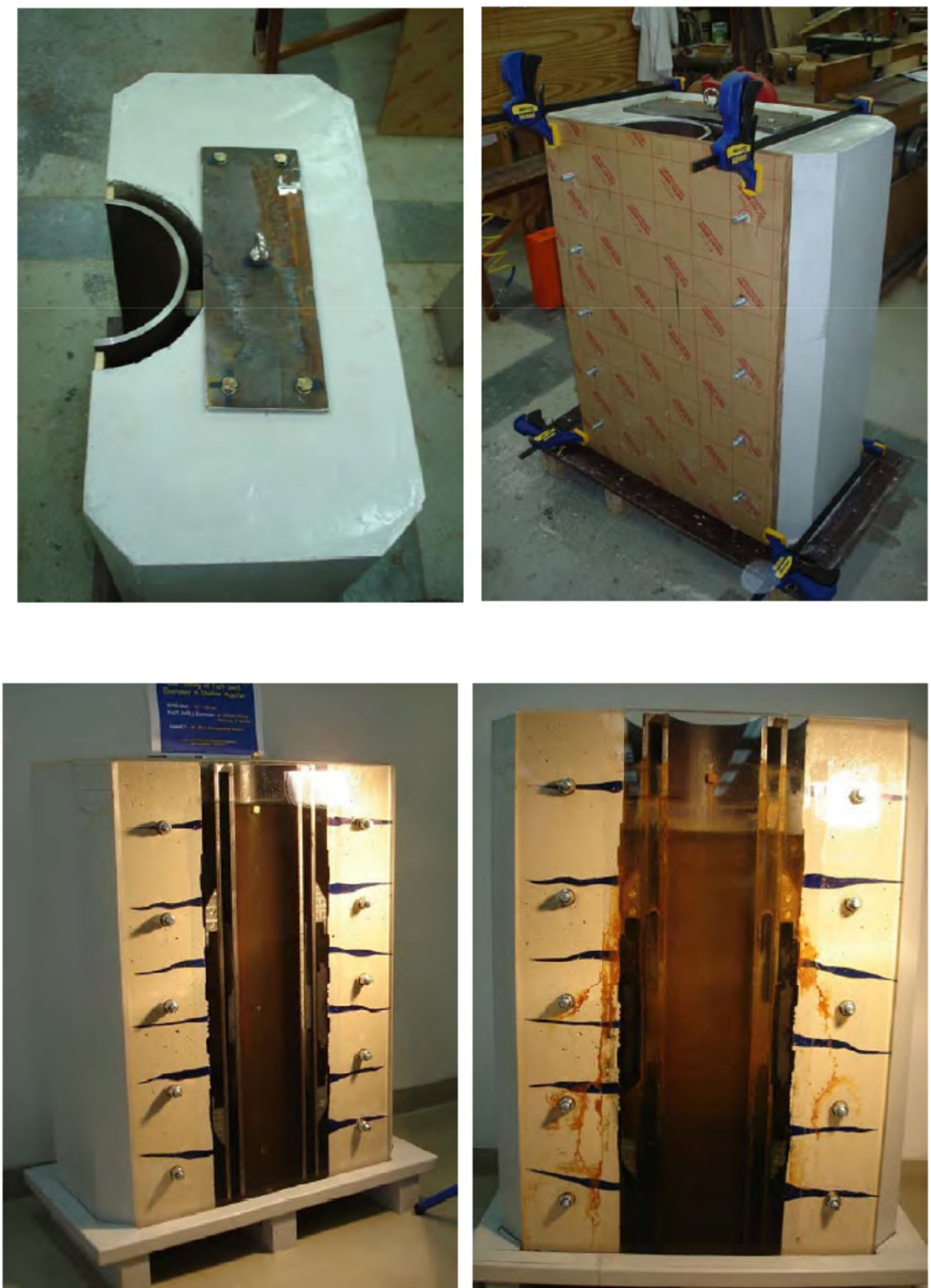

Fig. 7 Assembled unit after initial water fill-up (left); rust stains after 8 days of water exposure (right)
The inner swell packer (E2) was developed for wells with salinity ranging from 12 to $18 \%$, and working temperatures of $40-90{ }^{\circ} \mathrm{C}$. The current test unit could be tagged as a lowsalinity and medium-temperature environment. According to earlier laboratory tests (Patel et al. 2019; Qamar et al. 2009, 2016; Pervez et al. 2012), it was estimated to reach $70 \%$ swelling in 3 to 4 weeks. It was good to observe that the inner swell packer sealed against the steel casing in about 5 weeks, even though the salinity and temperature conditions were different. There was apprehension about the behavior of this elastomer under freshwater. However, it remained sealed against the tubular. Figure 9 pictorially describes the behavior of the outer fast-swell and the inner medium-swell elastomers before being exposed to water, and at various time periods after being submerged in water. Earlier studies concluded that if a low-salinity elastomer is exposed to highsalinity brine, or vice versa, the rate and amount of swelling can be significantly altered (Patel et al. 2019; Qamar et al. 2009, 2016; Pervez et al. 2012). The difference in expected and observed sealing times for the inside fast-swell packer and the outside medium-swell elastomer is therefore not surprising. 
Fig. 8 Flushing and cleaning of the unit for suspended rust particles (left); water fill-up after flushing (right)
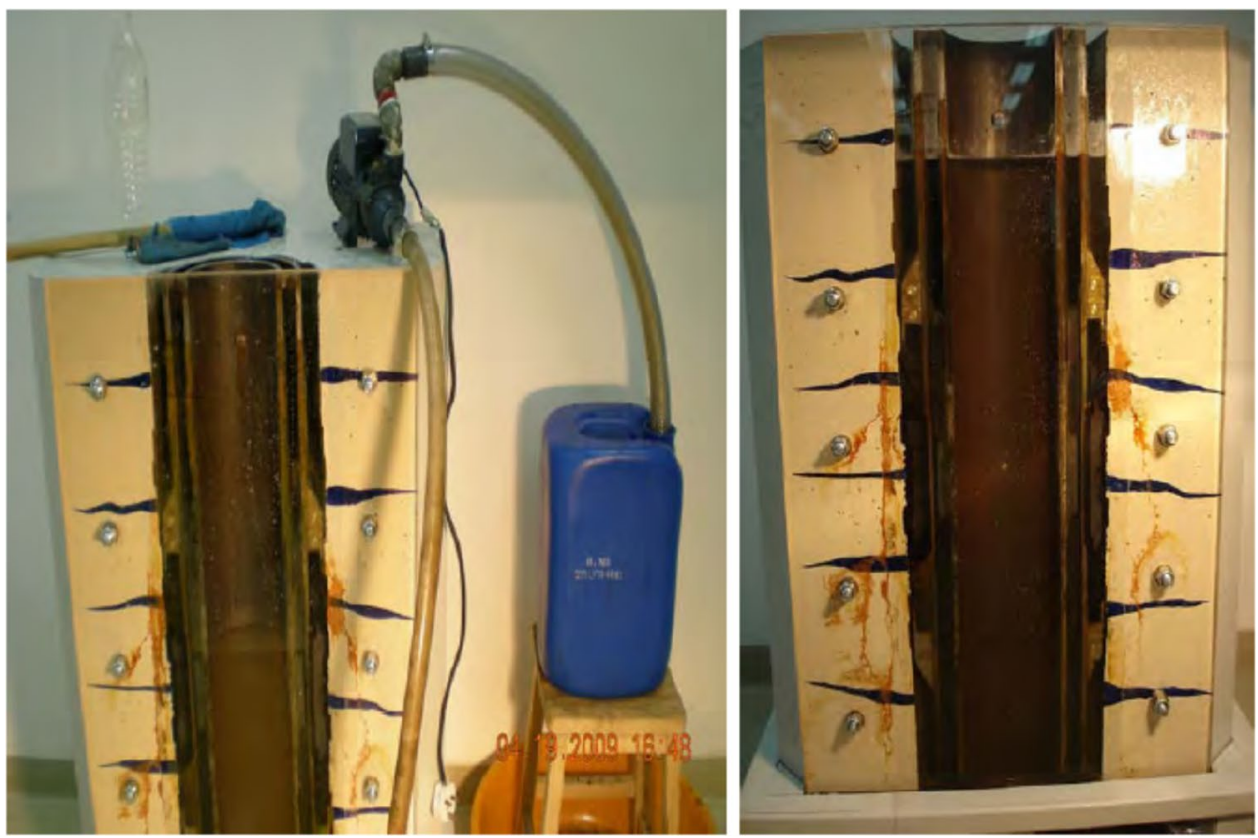

Water leaked out intermittently from the base or the sides, particularly at the interface between plexi-glass and the concrete block or the casing. Most of these leakages were stopped by applying higher torque on the bolts, thus increasing the tightness between the front-end plexi-glass to the concrete block. Also, steel pipes and bolts started to corrode after a few weeks, causing visibility problems once again. Shutting down the system, and performing repeated flushing and cleaning was unadvisable, especially as it was long-duration setup. A decision was therefore taken to disassemble the whole unit and perform a full-scale overhaul.

Thorough enquiry was again conducted about the most suitable water-shield paints for steels. The system was drained out, and swiftly transported back to the laboratory area, to maintain the same environment as before to prevent any notable de-swelling of the elastomers. The complete unit was taken apart and vigorously cleaned using wipes and different grades of sand and emery paper. Some steel bolts were replaced by non-corroding brass ones. Inner surfaces of the concrete half-block were painted over with several coats of the selected tank-guard protective paint. Tubulars and exposed bolts were covered with red oxide primer and differently colored weather-shield paints. This improved the corrosion-resistance and also made it easier to identify different sections and components. A fresh coat of epoxy was applied to the front wall of the concrete block before attaching the plexi-glass covers. However, due to the time taken in this overhaul process, the elastomer segments had de-swelled to a small degree.

Continuous exposure of elastomer, concrete, and metal components to stagnant water could lead to another problematic situation. Formation of algae and other biological forms can have other detrimental effects, coupled with reduction in visibility. Related search led to the identification of a chemical agent that hinders bacterial-biological growth in still water. After reassembly, the unit was filled again with water, together with a specific amount of the anti-bacterial chemical. The two packers went through a new round of swelling; Figure 10. Because of these remedial measures, the testing-demonstration unit showed continued higher visibility and zero leakage over a one-year period; Figure 11.

Dismantling the system gave a great unexpected benefit. No one has physically seen the actual shape or form of an elastomer seal once it completely swells against a steel casing or rock formation. However, as the system was disassembled, one could take a close look at the deshaped elastomer surface that swelled against the rough concrete. Figure 11 shows very interesting and unique photographs of this almost brain-like elastomer surface. Further investigation of this shape deformation and material response could reveal interesting physical and other causative phenomena associated with these patterns resulting from swelling and partial de-swelling of rubber type materials in general and swelling elastomers in particular.

\section{Conclusions}

Design, fabrication, and commissioning of an experimental-cum-demonstration unit were carried out. The target was extended-period investigation of the behavior of swelling and inert elastomer seals against an outer steel tubular, or rock formation of the borehole. Using wooden and polystyrene patterns, a concrete half-block

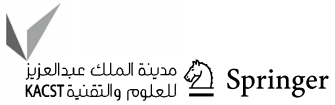


Fig. 9 Clear gap between elastomer segments and tubular before water filling (top-left); almost-complete sealing of outside packer while inside packer has swelled to some extent (topright); close-up view of swellsealing of outside packer against grooves of varying diameters and roughness in the concrete block (bottom)
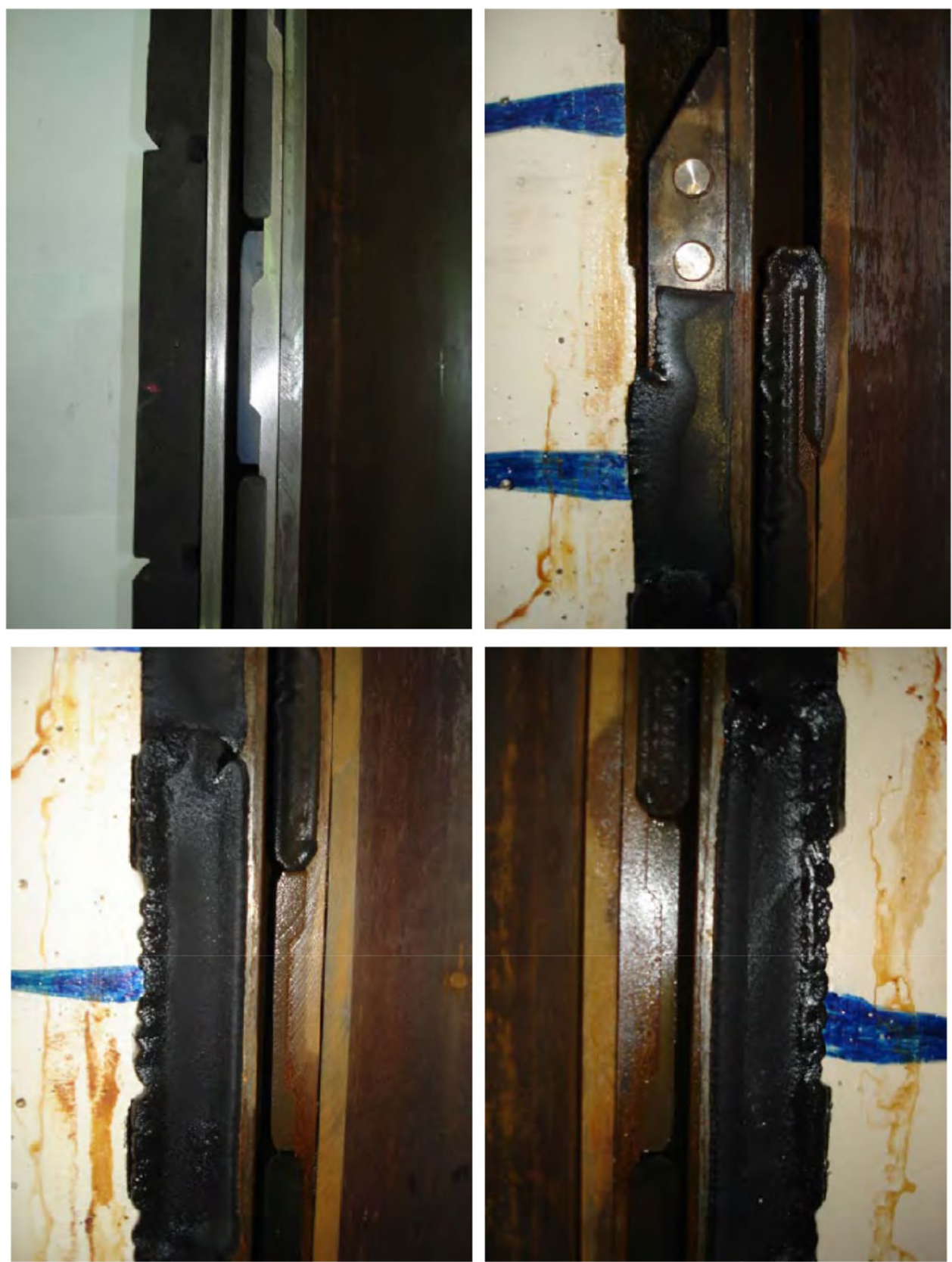

was designed and fabricated, with an internal surface containing sections of different diameters and roughness. Plexi-glass plates were fixed at the top and front to provide clear visibility. The inside packer (medium-swell elastomer) was to swell against a steel tubular, while the outer packer (fast-swell elastomer) on the casing was to swell against the formation-type rough concrete. Considering the significant difference between actual oil well and test unit conditions (saline water of $1 / 2 \%$ concentration at ambient temperature of about $50{ }^{\circ} \mathrm{C}$, in contrast to normal water kept at $20{ }^{\circ} \mathrm{C}$ temperature), results showing $70 \%$ swelling were very encouraging. Time taken for complete sealing (through swelling and filling of all irregular surfaces) was approximately 10 days for the fast-swell packer, and nearly 5 weeks for the medium-swell packer. Several types of repair and refurbishment activities were needed to achieve rust-proofing and leak-proofing of the test unit, together with prolonged higher visibility. Equally useful for field engineers, students, and researchers, this is a one-of-itskind experimental and demonstration unit, reproducing the behavior of swell packers in cased and open holes, and providing visual confirmation of the process of swelling of elastomer seals against casing and formation. 
Fig. 10 Reassembled test setup (after water drain-out, disassembly, washing-scrubbing, and repainting), showing small amount of de-swelling (top); elastomer segments re-swell after water is filled again (bottom)
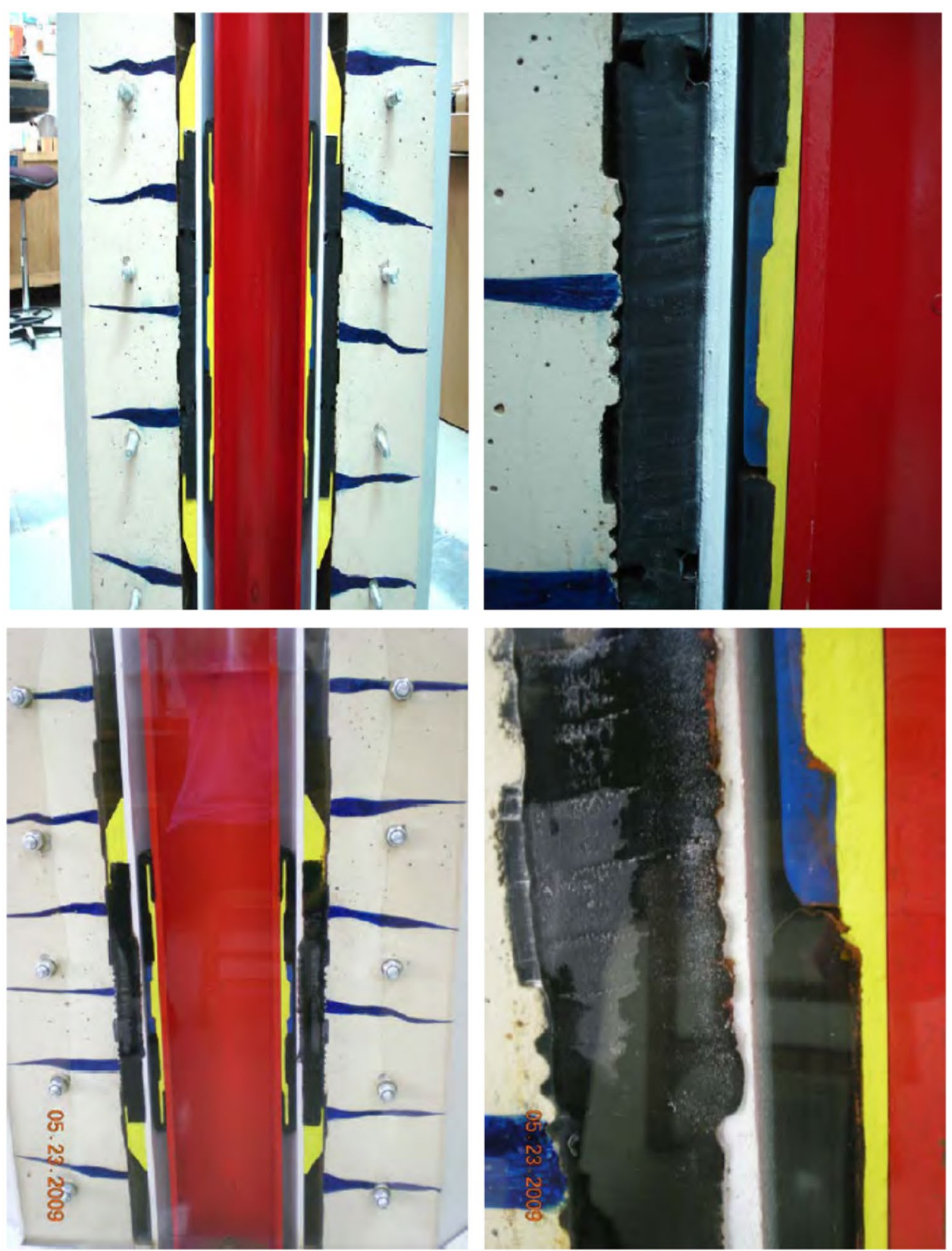

Fc' 
Fig. 11 Test-demonstration unit, one year after revamp and reassembly, showing swelling durability and clear visibility (left); normal and close-up views of patterns on elastomer surface, taken during disassembly stage, showing how it swells against rough formation or concrete block (right)

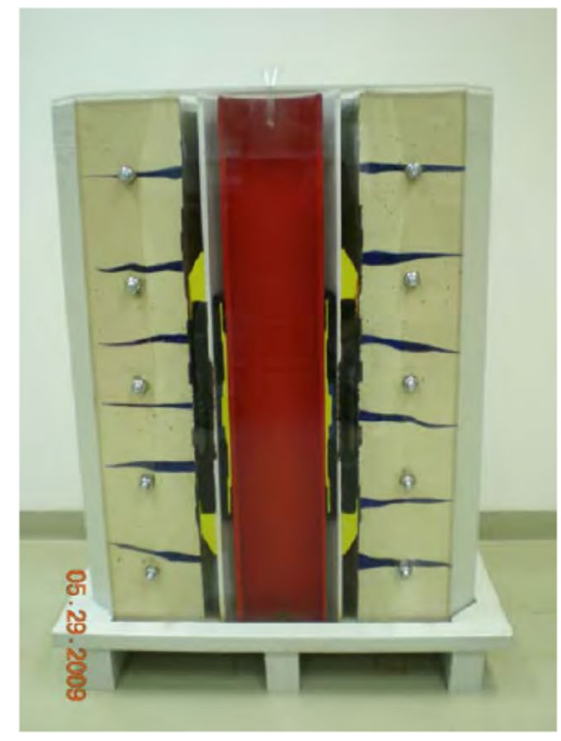

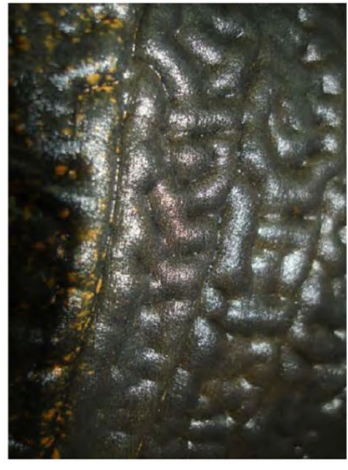

Acknowledgements The support provided by Sultan Qaboos University and Petroleum Development Oman is gratefully acknowledged.

Funding Funding for this work was provided by Petroleum Development Oman, and by Sultan Qaboos University (for use of in-house facilities).

\section{Declarations}

Conflict of interest There is no conflict of interest by any of the authors.

Ethical statement This is an original article, which has not been published before, and is not being submitted to any other journal for publication.

Open Access This article is licensed under a Creative Commons Attribution 4.0 International License, which permits use, sharing, adaptation, distribution and reproduction in any medium or format, as long as you give appropriate credit to the original author(s) and the source, provide a link to the Creative Commons licence, and indicate if changes were made. The images or other third party material in this article are included in the article's Creative Commons licence, unless indicated otherwise in a credit line to the material. If material is not included in the article's Creative Commons licence and your intended use is not permitted by statutory regulation or exceeds the permitted use, you will need to obtain permission directly from the copyright holder. To view a copy of this licence, visit http://creativecommons.org/licenses/by/4.0/.

\section{References}

Akhtar M, Qamar SZ, Mehdi SM, Hussain A (2018a) Diffusion-based swelling in elastomers under low and high-salinity brine. J Elastomers Plast 51(1):75-84

Akhtar M, Qamar SZ, Pervez T, Al-Jahwari FK (2018b) Performance analysis of swelling elastomer seals. Petroleum Sci Eng 165(2018):127-135
Al-Yami A, Nasr-El-Din H, Al-Saleh S, Al-Humaidi A, Al-Arfaj M, Awang M, Al-Mohanna K (2008) "Lab Investigation of Oil Swelling Elastomers for Smart Well," Paper \# SPE 19403, SPE Offshore Technology Conference, 5-8 May 2008, Houston, Texas, USA

Bell WT, Buzarde LE, DePriester CL, Kastor RL (1972) "Production Operations Course 1 - Well Completions," Dallas Texas 75206: Society of Petroleum Engineers AIME

Dorohov M, Kostryba I, Biletskyi V (2016) Experimental research on sealing ability of borehole packers. Eastern Eur J Enterprise Technol 82(4/8):56-68

Kamal MS, Sultan AS (2019) Enhanced Oil Recovery, in: Jafar MM, Sheardown H, Al-Ahmed A (eds) Functional Polymers, Polymers and Polymeric Composites: A Reference Series, Springer

Norton RL (2013) Machine Design: An Integrated Approach, 5th edition, Pearson Education

Oilfield Glossary (2019) “Packer,” Schlumberger, accessed Mar 2020, https://www.glossary.oilfield.slb.com/en/Terms/p/packer.aspx

Patel H, Salehi S, Ahmed R, Teodoriu C (2019) Review of elastomer seal assemblies in oil and gas wells: performance evaluation, failure mechanisms, and gaps in industry standards. J Petrol Sci Eng 179(2019):1046-1062

Pervez T, Qamar SZQ (2011) "Full Scale Testing of Fast Swell Packer for Shallow Aquifer Applications," Paper \# SPE/IADC 148533, SPE/IADC Middle East Drilling Technology Conference, 24-26 October 2011, Muscat, Oman

Pervez T, Seibi AC, Al-Hiddabi SA, Al-Jahwari FK, Qamar SZ, Marketz F (2007) "Solid Tubular Expansion in Horizontal Wells," SPE Paper \# 105704, 15th SPE Middle East Oil \& Gas Show and Conference, 11-14 March 2007, Bahrain

Pervez T, Qamar SZ, van de Velden M (2012) Comparison between fresh and exposed swelling elastomer. J Elastomers Plast 44(3):237-250

PetroWiki (2019) "Packer," https://petrowiki.org/Packers, accessed Mar 2020

Qamar SZ, Hiddabi SA, Pervez T, Marketz F (2009) Mechanical testing and characterization of a swelling elastomer. J Elastomers Plast 41(5):415-431

Qamar SZ, Pervez T, Akhtar M, Al-Kharusi MSM (2012a) Design and manufacture of swell packers: influence of material behavior. $\mathbf{J}$ Mater Manuf Process 27(7):721-726 
Qamar SZ, Pervez T, Akhtar M, Al-Kharusi MSM (2012b) Design and manufacture of swell packers: influence of Material Behavior. Mater Manuf Processes 27(7):727-732

Qamar SZ, Pervez T, Akhtar M (2016) Performance evaluation of water-swelling and oil-swelling elastomers. J Elastomers Plast 48(6):535-545

Rigzone (2019) “How Does a Swellable Packer Work?" accessed Mar 2020, https://www.rigzone.com/training/insight.asp?insight_id= 353\&c_id

Triolo MT, Anderson LF, Smith MV (2002) "Resolving the Completion Engineer's Dilemma: Permanent or Retrievable Packer?" Paper \# SPE-76711, SPE Western Regional/AAPG Pacific Section Joint Meeting, 20-22 May 2002, Anchorage, Alaska, USA
Wikipedia (2019) Production Packer. https://en.wikipedia.org/wiki/ Production packer. Accessed Mar 2020

Zeidan AA, Redha RA, Williams DD, Montero JE (2018) "Implementing WRFM Well, Reservoir, Facility Management and Smart Field Best Practices for EOR Optimization," Paper \# IDSPE-193693, SPE International Heavy Oil Conference and Exhibition, 10-12 December 2018, Kuwait City, Kuwait

Publisher's note Springer Nature remains neutral with regard to jurisdictional claims in published maps and institutional affiliations. 